\title{
SOME PRELIMINARY RESULTS FROM THE SOLAR MONITORING SATELLITE NRL 19641 D OBTAINED AT THE ARCETRI STATION
}

\author{
by M. Landini, M. Piatthili, G. Righini, D. Russo and G. L. Taglitafigri \\ (Osservatorio Astrofisico di Arcetri, Florence, Italy)
}

RÉsumt. - Ce travail comporte ; a) Une description de la station de télémétrie de Arcetri (Florence, Italie) qui permet l'enregistrement des mesures des rayonnements $X$ et $U V$ solaires.

b) Les valeurs du flux solaire à 44-60 ̊̊ en mars-avril 1964 obtenues par le satellite NRL 1964-01 $D$.

c) Un exemple typique d'absorption atmosphérique aux longueurs d'onde optique et $X$ au moment où le Soleil se lève pour le satellite.

d) La description des phénomènes particuliers qui se produisent quand le satellite traverse la ceinture subaurorale.

AвstRaCt. - This paper contains the following subjects; a) a description of the telemetry set operating in Arcetri (Florence, Italy) in order to record the measurements of solar $X$ and $U V$ radiation, via satellite :

b) the values of solar flux at 44-60 \& during the period March-A pril 1964, as deduced by telemetry of NRL 1964-01 D satellite :

c) a typical example of atmospheric absorption at optical and $X$-ray wavelengths during the sunrise on the satellite :

d) a particular feature of recording when the satellite passes through the sub-auroral belt.

Резюме. - Эта работа содержит :

a) Описание телеметрической станщии в Арчетри (Флоренция, Италия), позволяющей регистрирование измерений солнечных излучений $\mathrm{X}$ и ультра фиолетовых.

b) Значения солнечного потока в $44-60 \AA$ п 8. 14 А марте - апреле 1964, полученные спутником NRL 1964 - OID.

c) Типичный пример атмосферного полгощения в длине волн оптических п $\mathbf{X}$ в момент восхода Солнца для спутника.

d) Описание особых явлений происходящих когда спутник проходит через подваревой пояс.

On January 11 the N. R. L. launched the satellite 1964.01-D instrumented for the measurement of solar X-rays and ultraviolet radiation during the Quiet Sun Year. The satellite is provided with photometers sensitive to the flux of X-rays in the bands $0-8,8-20,44-60 \AA$ and to the ultraviolet radiation (1225-1350 $\AA$ ). A complete description of the instrumentation has been presented at the VII COSPAR Symposium by R. W. KREPLIN (1964a).

The satellite signals have been received and recorded at Arcetri. Although passages were occasionally received and recorded in January and February, daily data have been obtained by this station since the $1^{\text {st }}$ of March.

\section{a) Instrumentation.}

The receiving station, in operation since July 1962, is composed of the following items :

1. A fully steerable antenna, altazimuth mount, composed of an array of 8 yagi's, each with 4 ele- ments ; the gain is of $20 \mathrm{db}$ and the main lobe is of $120 \times 24^{\circ}$.

The vertical lobe is the larger in order to provide longer time coverage of the horizon.

The antenna is powered by two motors; while two potentiometers provide the angle pick-off devices.

2. A low noise preamplifier, with the configuration of grounded grid followed by cascode, provides a gain of $30 \mathrm{db}$ with a noise factor of $4 \mathrm{db}$ and a bandwidth of $1.5 \mathrm{MHz}$. This preamplifier is mounted directly on the antenna.

3. A quartz controlled converter reduces the signal from 136.8 $\mathrm{MHz}$ to the frequency of 16.8 MHz. This is further amplified by a communication receiver which can be tuned over this IF and provides the overall receiver selectivity of approx. $10 \mathrm{KHz}$.

4. The demodulated output is recorded on a double track magnetic tape after being mixed with a constant note of $5400 \mathrm{~Hz}$.

On the second track, time marks and voice signals are recorded for identification. 
5. The output of the magnetic tape is sent to a decoder provided with 6 IRIG channel filters (viz. 3-4-5-6-7-8).

These filters are switchable and their outputs are applied to a frequency meter.

The note of $5400 \mathrm{~Hz}$ is independently filtered and applied to a second frequency meter identical to the first one.

6. A pen galvanometer records the voltage differences of the output of these two frequency meters. Therefore the final information carried by each IRIG channel, as differential frequency modulation of $\pm 7,5 \%$, is recorded independently of any flutter added by the magnetic tape recorder.

The overall signal to noise ratio, "necessary to lock the decoder, is such that it is possible to have a readuble recording as soon as the satellite appears on the horizon. The number of satellite passages recorded at Arcetri from January to July 31 of 1964 is on the whole 172.

\section{b) Observations.}

The values of the solar flux at 44-60 $\AA$ (channel 5) measured during the months of March and April are plotted in Fig. 1, except the interval 15 March-7 April because of the high value of the aspect angle. The solar flux ranges between 2.0 and $4.010^{-2} \mathrm{erg} \mathrm{cm}^{-2} s^{-1}$ : the same order of magnitude was measured by the satellite N. R. L. 1963-21 C (T. A. CHOBB, 1963) and by the present satellite (KREPLIN 1964a). During the time of a 5-15 minute passage no solar flux variations have been observed. Channel 7 (8-14 $\AA$ ) gives generally a signal of zero except on the days 10,11 , 13, 18, 24 of April, when it gave a very small, but visible signal. Channel $6(1225-1350 \AA)$ shows an oscillating signal when the satellite is in sunlight as well as when it is in darkness : the signal is probably due to the ion collection by the unshielded U. V. photometers (KREPLIN, 1964b).

Fig. 2 shows the atmospheric absorption at optical and X-ray wavelengths.

From the absorption curve of the $X$-rays it is possible to calculate the atmospheric density, if the absorption cross sections? are known. From a provisional calculation, with the cross section given by NICOLET and'ATKIN (1960) we'obtained a set of atmospheric density values in the altitude range of 100-180 km : these values are less than those from the C. I. R. A. (1960) by a factor 2,5. Calculations based on other similar events are being made.

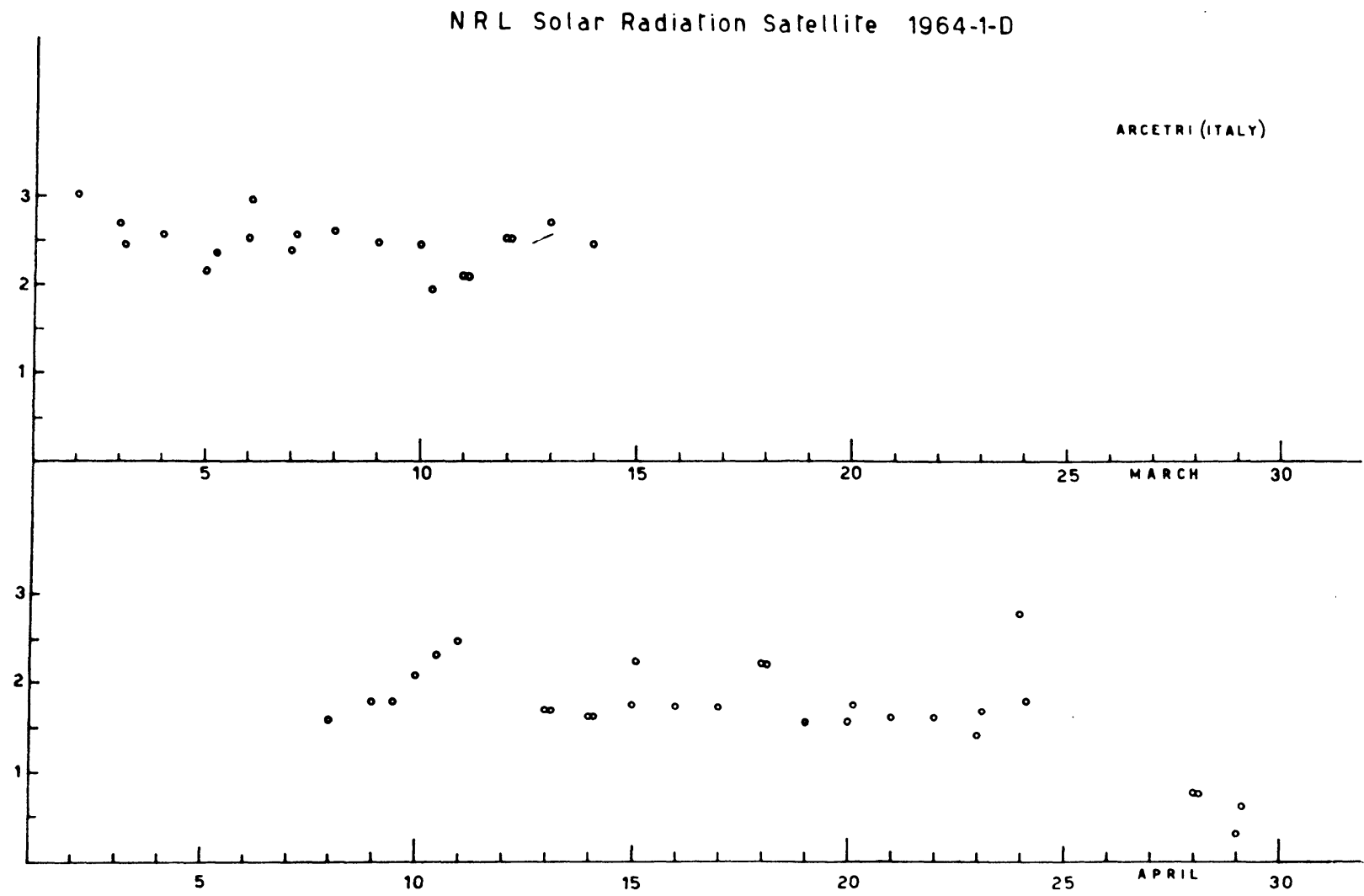

Fra. 1. - Reduced solar X-ray flux data (44-60 $\AA$ ) for the period 1-st March 30-th April 1964. (Telemetry station of Arcetri) Units of $10^{-2}$ ergs $\mathrm{om}^{-2} 8^{-1}$. 
A particular feature on channels 5 and 7 has been observed, which consists in additional signals which appear twice at each rotation of the satellite. Such signals are not always present on the recording but begin to grow when the subsatellite geomagnetic latitude is greater than about $55^{\circ} \mathrm{N}$. These signals are observed alone or accompanying the solar signal depending on the aspect angle of the satellite (Fig. 3).

Fig. 4 shows the subsatellite points corresponding to the beginning of the multiple signal : these points seem to be aligned along a geomagnetic parallel near the superior boundary of the subauroral belt. Similar observations have been made

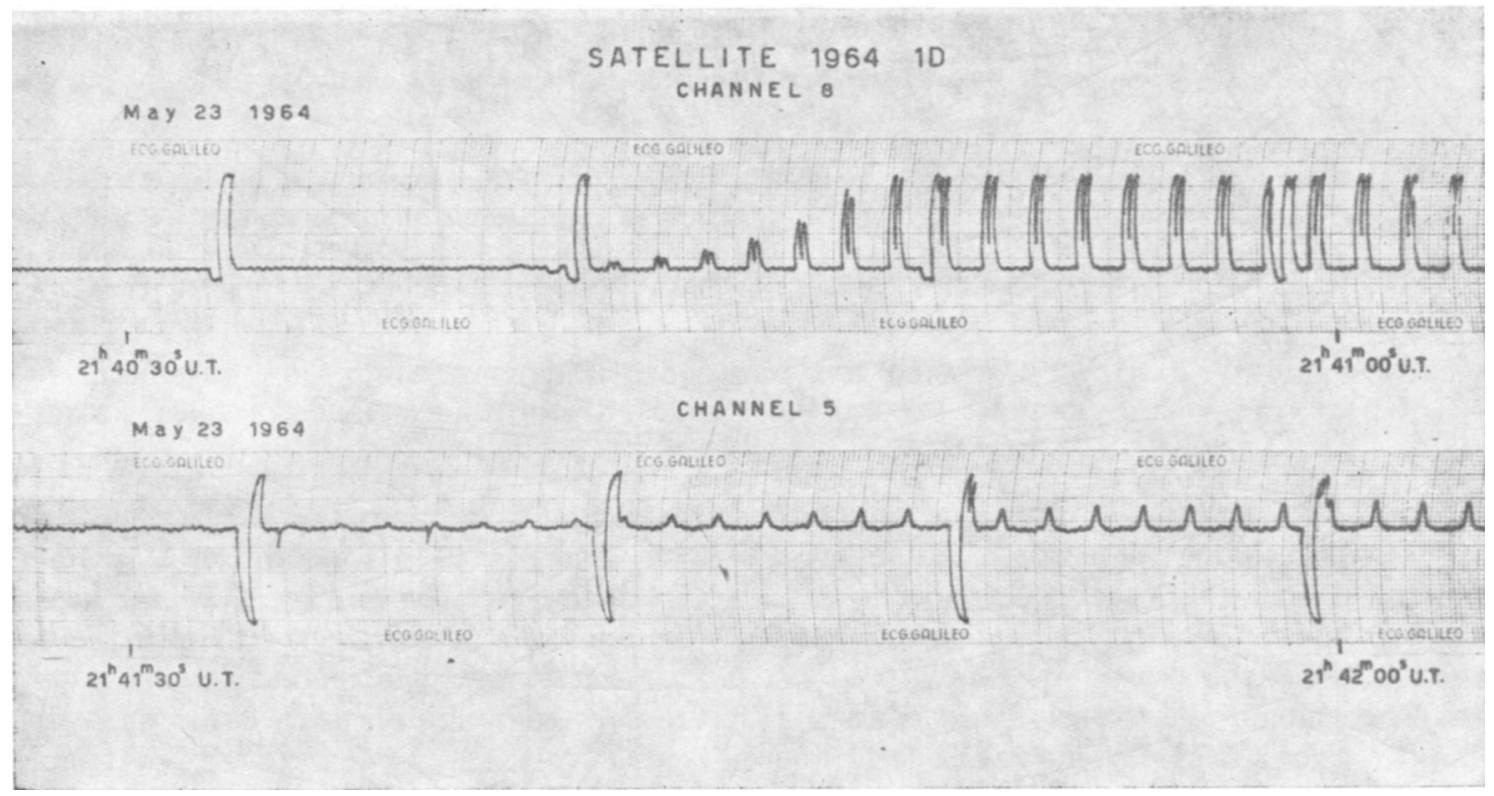

Fia. 2. - Recordings of the aspect ohannel (upper part) and 44-60 \& X-rays ohannel (lower part), showing the sunrise for the satellite. Note that the sunrise in visible light occurs approximately 1 minute before the $X$-ray, with shorter rise time.

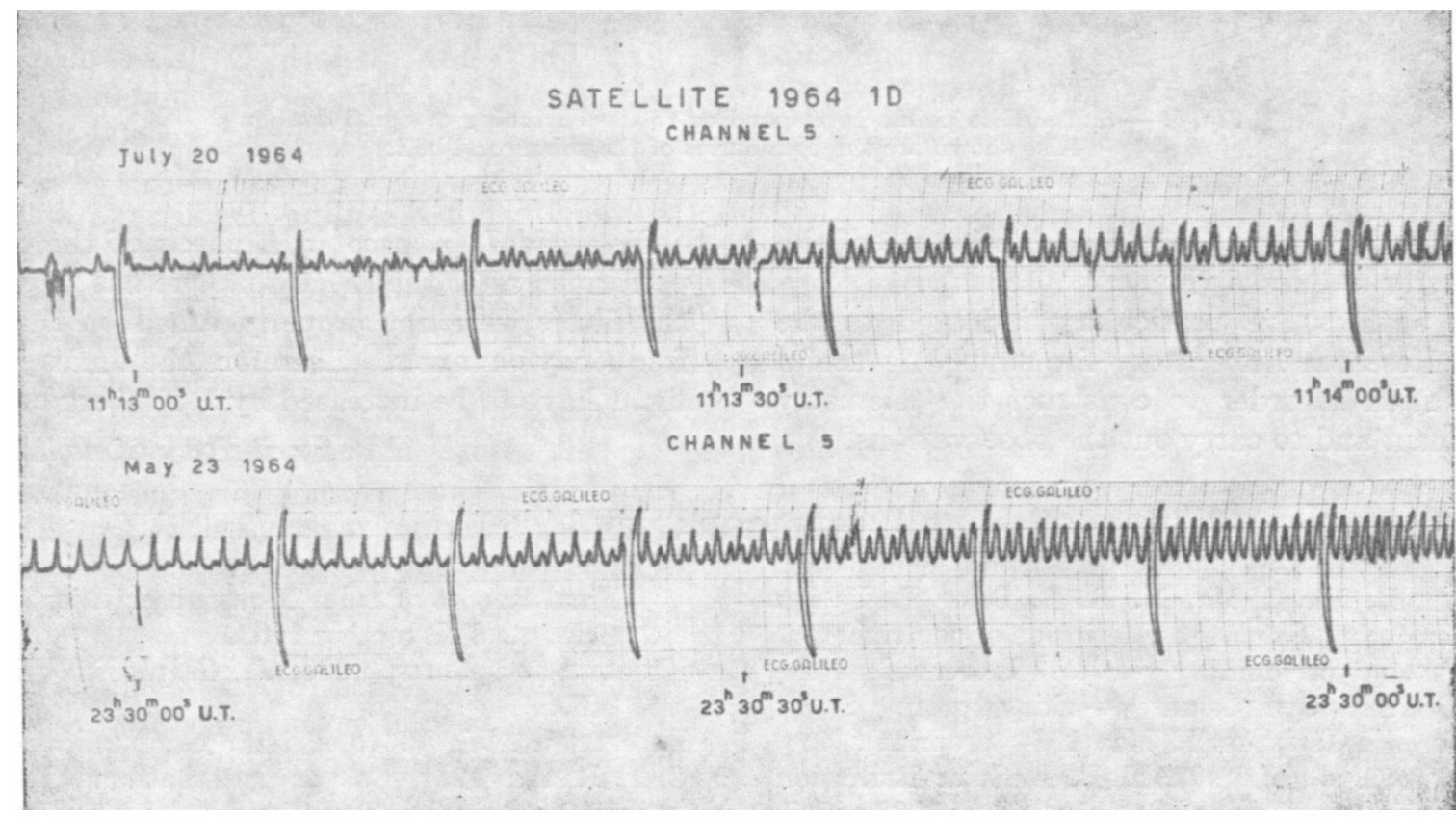

Fra. 3. - Two typical recordings of channel 5 (44-60 A) showing the doubling of the signals. 


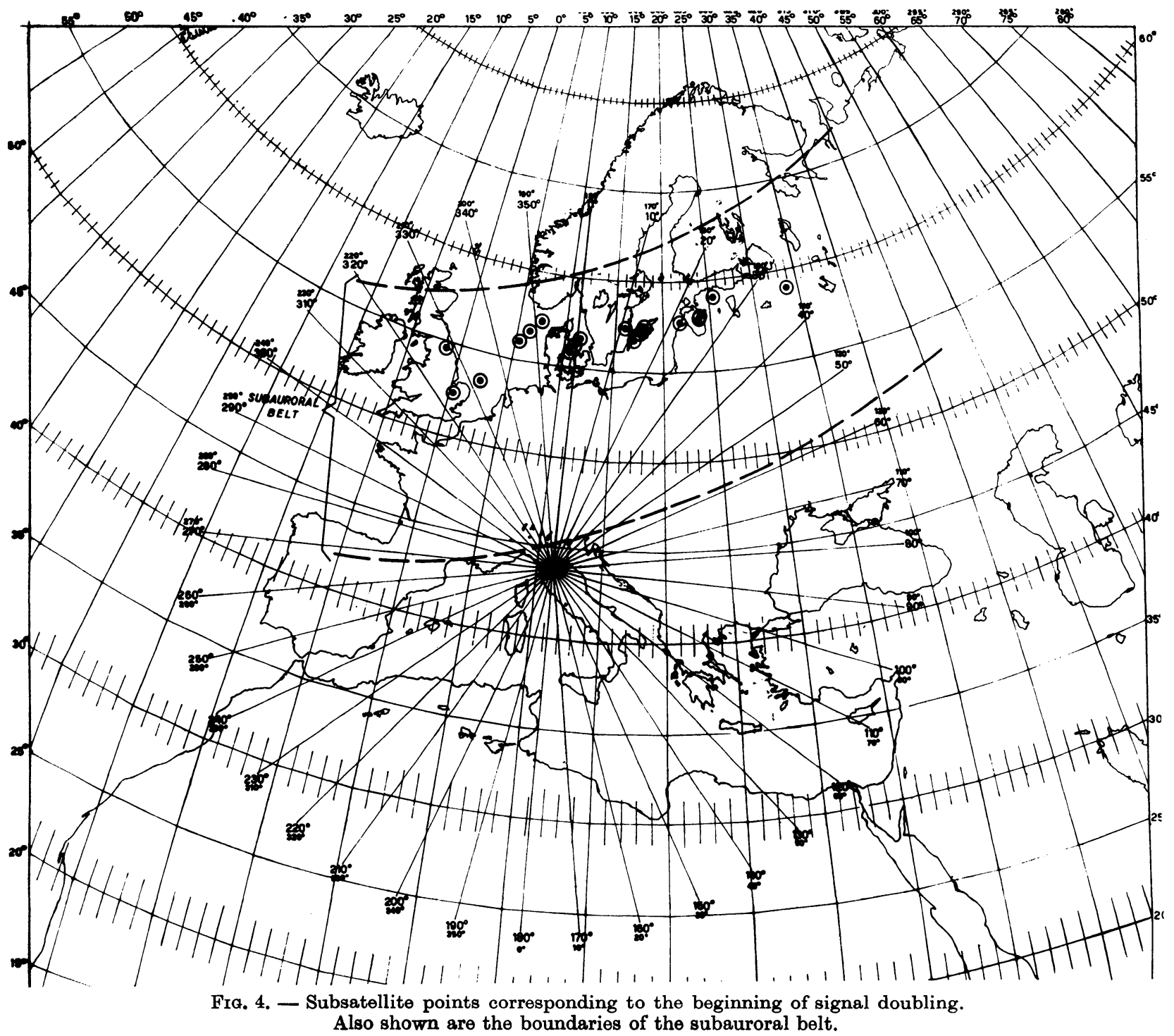

at the station of the Geophysical Institute of the University of Alaska (KREPLIN, 1964a).

The authors are particulary indebted to the Naval Research Laboratory for supplying useful information in order to construct the telemetry equipment and to carry out the observations.
Note added in proof : A check of the decoder performed after the Liège Colloque has shown that the filters were not properly tuned on the IRIG frequency channels. Therefore the fluxes read on fig. 1 have to be increased by $110^{-2} \mathrm{erg} / \mathrm{cm}^{2} \mathrm{~s}$.

Manuscrit reçu le 22 aout 1964.

\section{BIBLIOGRAPHY}

Kreplin R. W., 1964a, N. R. L. Solar Radiation Monitoring Satellite : description of instrumentation and preliminary results. Presented at the COSPAR Symposium (working group 2) at Florence, Italy, on 11 May 1964 (preprint).

Chuвв T. A. et alii, 1963, N. R. L. Solar Radiation experiment Cospar Satellite No. 1963 21-C.
Final Report of Solar X-ray observations to participants 8 November 1963.

Nicolet and Aikin, 1960, J. Geophysical Res. 65, 1469.

Kreplin R. W., 1964b, Private communication.

C. I. R. A., 1961 Cospar International Reference Atmosphere North Holland Publishing Company, Amsterdam. 